удк 343.1

\title{
И. И. Чугуников
}

\section{КРИЗИС УГОЛОВНОГО ПРАВА ИЛИ УГОЛОВНОЕ ПРАВО КРИЗИСА?}

В современной уголовно-правовой теории, как зарубежной [1, с. 130-134; 2 , с. 67], так и отечественной [3, с. 40-46; 4, с. 5-6], при оценке состояния уголовно-правовой доктрины, уголовного законодательства и правоприменения все чаще ключевым тезисом становится тезис о кризисе (системном кризисе) уголовного права.

Как отмечает В.А. Туляков, происходит виртуализация правовой нормы, при которой формальное наличие запрета нейтрализуется необязательностью либо невозможностью (материальной или процессуальной) его исполнения $[4$, с. 5]. В целом кризисные явления в уголовной отрасли анализируются исключительно в негативном плане и рассматриваются в качестве серьезных препятствий на пути к оптимизации уголовно-правовой системы. На самом деле сам по себе отраслевой кризис никакой опасности для уголовно-правовой системы не представляет. Наоборот, это вполне закономерное и при всей парадоксальности данного суждения довольно прогрессивное явление. Кризис отрасли свидетельствует об определенном итоге ее развития в рамках сложившейся социальной формы и необходимости ее трансформации вместе с изменяющимся социальным порядком. А.О. Кистяковский справедливо отмечает: «Процесс развития и видоизменения уголовного права есть процесс органический, то есть совершающийся по неизменным законам, присущим природе обществ человеческих. Он не есть самостоятельный в том смысле, чтобы уголовное право развивалось и видоизменялось, само из себя и само для себя, но подчиненный, так как развитие и видоизменение уголовного права есть результат развития и видоизменения разнообразных общественных и частных отношений, а вместе с тем и миросозерцания человека как существа общественного» [5, с. 120]. Именно кризис уголовного права способствовал появлению уголовной антропологии, социологии, естественно-научного направления. Спустя время повторившийся кризис породил теории неоклассицизма и новой социальной защиты, идеи аболиционизма и рестаративной юсти- 
ции, тезисы о необходимости альтернативы лишению свободы и альтернативы уголовному наказанию как таковому. Поэтому, как представляется, опасность заключается не в самом кризисе, а в выборе возможных путей его преодоления. Уголовно-правовая система - довольно сложное образование, к составляющим которого относят доктрину уголовного права, уголовно-правовую политику, уголовное право как отрасль права, уголовное законодательство, уголовное право как учебную дисциплину, применение уголовно-правовых норм, уголовное правосознание населения и правоприменителей, международное материальное уголовное право [6, с. 902-903].

Однако учитывая то обстоятельство, что системообразующим фактором, объединяющим указанные элементы в единую систему, выступает уголовное право как материальная отрасль, все усилия науки и законодателя по преодолению кризиса сосредотачиваются именно здесь. Плод этих усилий может быть двояким: либо уголовно-правовая форма начинает соответствовать социальным запросам и возможностям, что свидетельствует о преодолении кризиса, либо уголовно-правовая форма развивается искусственно, сама по себе, не только без учета складывающихся реалий, но и без учета собственных постулатов. Так, в Особенной части Уголовного кодекса Украины (далее - УК Украины) появляются не известные Общей части виды наказаний, например, ограничение права занимать определенные должности или заниматься определенной деятельностью (ч. 4 ст. 2201), тогда как в ст. 55 УК Украины речь идет о лишении права, устанавливаются не известные Общей части сроки основных (ч. 1 ст. 213 УК Украины предусматривает наказание в виде ограничения свободы на срок до одного года, тогда как в соответствии со ст. 61 УК Украины минимум установлен в один год) либо дополнительных (согласно ч. 4 ст. 2201, ст. $220^{2}$ и ч. 1 ст. $365^{2}$ УК Украины установлено дополнительное наказание в виде лишения права занимать определенные должности или заниматься определенной деятельностью на срок до 10 лет, хотя в соответствии со ст. 55 УК Украины он не может превышать 3 лет) наказаний, что в итоге ведет к образованию специфического феномена - уголовного права кризиса. Формирование этого феномена, как представляется, связано прежде всего с завышенной оценкой роли уголовно-правовых предписаний со стороны власти.

В отечественной общетеоретической юриспруденции особое место среди отраслей права традиционно отводится конституционному праву. С учетом системообразующего влияния на формирование структуры права эту отрасль, как правило, называют фундаментальной, имеющей интегративный характер, содержащей в себе основные начала системы права, воплощающей идею конституционализма и выполняющей решающую роль не только в публичном, но и в частном праве [7, с. 133]. Уголовному же праву, и это опять-таки традиция, в общей теории права отводится куда более скромная роль. Его определяют в качестве разновидности так называемых основных отраслей (гражданского, административного, трудового), особенностью которых является их юридическая безупречность 
и соответствие правового режима качественным характеристикам отрасли. Не оспаривая по сути этот общераспространенный постулат, хотелось бы заметить, что роль и значение уголовного права в жизни социума не так однозначны. На обывательском уровне все юридическое многообразие сводится фактически к уголовному правоприменению (по принципу «посадят - не посадят», как обеспечить достойное существование себе и своим близким, чтобы этого не случилось), и только после решения главной жизненной задачи на повестку дня для обсуждения могут быть поставлены вопросы политического, экономического, интеграционного и иного будущего страны. На официальном уровне отношение к уголовному праву уже не просто приоритетное, а благоговейное. И дело не только в определенном ожидании последствий неоправданно широкого использования уголовного права в виде укрепления авторитаризма власти, блокирования развития гражданского общества, усиления позиций правоохранительных структур, деформации целей социального развития, нелегальной приватизации власти и так далее [8, с. 197]. Суть проблемы заключается в систематических, абсолютно необоснованных попытках государства решить весь комплекс экономических, политических, идеологических, этнических, религиозных, социокультурных и иных вопросов с помощью законотворчества и правоприменения в уголовно-правовой сфере. И зачастую именно уголовно-правовые предписания являются первыми и последними аргументами власти в борьбе за построение «светлого будущего». Не случайно в последнее время, причем уже далеко не в шутку, Уголовный кодекс Украины все чаще называют «криминальной конституцией» или «конституцией с санкциями». Уже одно это обстоятельство позволяет выделить уголовное право из череды основных отраслей и придать ему особый статус. Действительно, уголовное право обладает рядом внутренних специфических характеристик, имманентно присущих только ему. Главные из них, на наш взгляд, - это способность к достаточно жесткой социальной стратификации, то есть разделению общества на два порой непримиримых лагеря (законопослушных и преступников, «своих» и «чужих», «наших» и «не наших»), и способность к наиболее значимому ущемлению конституционного статуса личности. Эти природные черты в процессе правоприменения вполне могут быть усилены за счет использования так называемого провокативного эффекта [9, с. 85], когда ординарному уголовному производству с банальной квалификацией задается соответствующий конъюнктурный вектор, способный вызывать необходимый общественный резонанс. Однако исключительность уголовного права, с нашей точки зрения, определяется отнюдь не этим. С момента своего зарождения и по сегодняшний день основное предназначение этой отрасли права сводится к обеспечению устойчивости социума, удержанию его на цивилизационных рельсах, предотвращению скатывания в бездну хаоса и неопределенности. Поскольку решение этой задачи возможно только благодаря усилиям каждого члена социума, уголовно-правовые предписания должны быть просты, доступны, а самое главное - стабильны. Истинное 
величие уголовного права, как представляется, заключается в верности традициям, прежде всего отечественным, в устойчивости к конъюнктурным колебаниям, в отшлифованных веками принципах и конструкциях, в кристаллизовавшихся столетиями основных функциях, в апробированных многолетней практикой методах разрешения уголовно-правовых конфликтов. Весьма показательным в этом плане является суждение профессора Л.Е. Владимирова, высказанное более ста лет тому назад при оценке нового уголовного законодательства стран Западной Европы: «Новейшие кодексы не представляют ничего нового в существенных основах уголовного законодательства, хотя дают технические улучшения и отражают успехи гуманизации всего дела уголовного правосудия в подробностях. Уголовное законодательство слишком тесно связано с целым социальным строем, чтобы в его системе самостоятельно могли проявляться перемены в основных началах» [10, с. 386]. Широкомасштабная ревизия устоявшихся понятий, зачастую имеющая сугубо идеологическую подоплеку, механическое заимствование уголовно-правового материала не только из законодательства других стран, но и из законодательства стран других правовых систем, слепая имплементация положений международных конвенций, перманентные изменения национального уголовного законодательства, обусловленные не объективной необходимостью, а сиюминутным желанием залатать финансовые дыры, отсутствие какой-либо стратегии развития уголовно-правовой отрасли вполне способны создать ситуацию, когда вместо величия появляется его антипод.

Традиционная ставка законодателя на уголовно-правовые возможности в преодолении всех общественных бед оказывается иллюзорной и, как следствие, проигрышной. Это совершенно естественно, поскольку уголовное право объективно не в состоянии решать задачи такого рода. Можно как угодно усиливать наказание за использование малолетнего ребенка для занятия попрошайничеством (ст. 1501 УК Украины), ситуация не изменится, пока у матери реально не появятся средства на его содержание. Однако законодатель, да и большей частью доктрина по-прежнему усматривают суть проблемы не в отсутствии соответствующих экономических, политических и других решений, а в несовершенстве уголовно-правовых предписаний, их заидеологизированном характере, неспособности имеющегося уголовно-правового инструментария противодействовать преступности, неэффективности традиционных уголовно-правовых мер и так далее. В итоге рождается идея о кризисе уголовного права, которая обуславливает появление новой иллюзии: в результате преодоления кризиса уголовное право все же обретет сверхвозможности и будет способно к решению любых задач.

В эпоху независимости преодоление уголовно-правового кризиса логичнее всего было начать с активной критики теоретического наследия советского периода. Поскольку краеугольным камнем отечественной доктрины являлось учение об объекте, в первую очередь досталось именно ему. Все достижения советской уголовно-правовой науки в этом вопросе, 
затраченные ею усилия по исследованию феномена общественных отношений и их результаты были отвергнуты с необыкновенной легкостью. Фундаментальные работы, посвященные объекту преступления, были признаны насквозь заидеологизированными, а их авторы объявлены пленниками длительное время внедрявшихся в юридическую науку априорных и абстрактных штампов и шаблонов.

Действительно, официальная идеология требовала в первую очередь обеспечения всеми способами безопасности нового социального порядка и рассмотрения любого уголовно-правового конфликта прежде всего и главным образом с классовых позиций. Поэтому ни одна серьезная работа по праву, тем более уголовному, не могла обойтись без ссылок на «первоисточники» и руководящие партийные документы. Однако утверждение о том, что, например, Б.С. Никифоров, Н.И. Коржанский, В.К. Глистин, В.Я. Таций и другие ученые всерьез искали обоснования собственных взглядов в решениях очередного съезда партии, постановлениях пленумов ЦК или трудах классиков марксизма-ленинизма, мягко говоря, грешит против истины. Наличием идеологических нюансов, пусть и большого количества, содержание их трудов явно не исчерпывалось. Более того, при тщательном анализе трактовки объекта как общественных отношений вполне можно усмотреть параллели с отечественной уголовно-правовой теорией на рубеже XIX - XX веков, где понятие объекта сводилось к «юридическим отношениям», «отношениям людей друг к другу или юридическим установлениям», «правосостоянию как быту государственному», «порядку общественных отношений» и так далее. А это значит, что наука уголовного права советского периода, во-первых, придерживалась отечественных традиций в исследуемом вопросе, хотя ее и не устраивало представление об обществе как едином целом; во-вторых, она смогла преодолеть сковывающие досоветскую уголовно-правовую доктрину рамки права. Заметим, что в западной уголовно-правовой теории сколь-нибудь серьезного учения об объекте так и не было создано, в связи с чем он никогда не рассматривался в качестве самостоятельного элемента состава, в отличие от отечественной доктрины, где объект выполняет именно такую роль. Отсутствие объекта как элемента состава означает отсутствие основания уголовной ответственности (ч. 1 ст. 2 УК Украины). Однако, несмотря на это, призыв был услышан. Уголовно-правовая литература буквально наводнилась «новыми» подходами к определению понятия объекта. Его начали связывать с «правовыми благами», «социальными ценностями», «человеком», «определенной социальной общностью», «социальной оболочкой», «правами и свободами граждан» и прочим. Не вдаваясь в полемику по поводу научной состоятельности этих «новомодных» течений, отметим главное: концепция «объект - общественные отношения» была серьезно расшатана, а взамен фактически ничего не создано. В изданиях последних лет, посвященных проблемам квалификации тех или иных преступлений, об объекте либо вообще не упоминается, либо это делается вскользь, отда- 
вая дань традиции, либо предпринимается попытка на «всякий» случай упомянуть все.

Так, например, авторы коллективной работы «Окружающая среда как объект уголовно-правовой охраны», поддерживая идею о перемещении ст. 268 УК Украины («Незаконный ввоз на территорию Украины отходов и вторичного сырья») из раздела IX «Преступления против общественной безопасности» в раздел VII «Преступления против окружающей среды», приходят к выводу, что объектом этого преступления выступает окружающая среда как определенная ценность (благо). Это благо, по представлению авторов, состоит из отдельных элементов либо объектов, на которые посягают те или иные деяния, ответственность за которые предусмотрена разделом VIII УK Украины. Эти элементы определяются следующим образом:

- нарушение правил экологической безопасности (ст. 236 УК Украины) посягает на общественные отношения по охране окружающей природной среды и экологическую безопасность населения;

- непринятие мер по ликвидации последствий экологического загрязнения (ст. 237 УК Украины) посягает на экологические права граждан, в первую очередь на право экологической безопасности;

- сокрытие или искажение сведений об экологическом состоянии или заболеваемости населения (ст. 238 УК Украины) посягает на конституционное право граждан на экологическую информацию;

- незаконная порубка леса (ст. 246 УК Украины) причиняет вред общественным отношениям по охране леса и лесных насаждений;

- незаконное занятие рыбным, звериными или иным водным добывающим промыслом (ст. 249 УК Украины) причиняет вред общественным отношениям по охране водных биологических ресурсов;

- общественные отношения по охране окружающей среды - основной непосредственный объект проектирования или эксплуатации сооружений без систем защиты окружающей среды (ст. 253 УК Украины) [11, с. 56, $59,63,73]$.

Авторов, пожалуй, нельзя упрекнуть только в том, что они не упомянули какую-либо из известных концепций объекта преступления.

Постепенно объект утрачивает свой статус необходимого элемента состава. И это несмотря на то, что связь между ним и общественной опасностью (по крайней мере, на данный момент) является генетической. В результате широкомасштабной ревизии концепции «объект - общественные отношения» стало ясно одно: решить проблему объекта вне отношенческой плоскости невозможно, поэтому вместо «общественных отношений» стали появляться иные социальные категории. Однако многие разработки в рамках учения об объекте, носящие сугубо прикладной характер, уже преданы забвению. Например, на сегодняшний день абсолютно непонятно, по каким критериям необходимо проводить разграничение между сложным единичным многообъектным преступлением и множественностью преступлений (особенно в условиях полной разбалансированности санкций); подлежат ли уголовно-правовой охране интересы одной из сторон в 
преступном (например, киллер получает вознаграждение и не выполняет обещанное, должностное лицо получает неправомерную выгоду и действует вопреки интересам выгододателя) или ином антисоциальном отношении (например, при игре в карты один из участников ставит на кон банковскую карту, утверждая что на ней имеются солидные средства, тогда как на самом деле карта пуста) и так далее. Говорить о возможности унификации правоприменительной практики в создавшейся ситуации, увы, не приходится.

Однако уголовно-правовая теория, невзирая на эти «нюансы», заметно теряет интерес к проблематике объекта, и на авансцену вырывается другая идея - идея о необходимости приведения отечественного уголовного законодательства в соответствие с европейскими стандартами. Где они изложены и как выглядят, неясно. Но очевидно другое: во главе угла должен находиться человек.

Законодатель подхватывает эту идею и начинается интенсивная ломка «старой»и, конечно, «реакционной» нормативной базы, обеспечивающей примат общественных интересов над частными. Конституции новых независимых государств провозглашают человека, его жизнь и здоровье, честь и достоинство, неприкосновенность и безопасность наивысшей социальной ценностью (ст. 3 Конституции Украины), а уголовные кодексы некоторых республик (например, Российской Федерации, Республики Армения), следуя европейским «стандартам», перемещают преступления против жизни и здоровья личности на первое место в системе особенной части. В качестве приоритетной задачи правовое обеспечение охраны прав и свобод человека и гражданина провозглашает также УК Украины (ч. 1 ст. 1). Однако в результате повального «окумиротворения» прав и свобод человека революции, к сожалению, не произошло. Более того, оказывается, что обеспечить надлежащую защиту наивысшей социальной ценности абсолютно невозможно в условиях, когда слабы и недееспособны государственные институции. Кроме того, выясняется, что та же Европа придерживается и других «стандартов». Так, например, Уголовный кодекс Бельгии предусматривает ответственность за преступления против жизни только в восьмом разделе, а Уголовный кодекс ФРГ - в шестнадцатом. Однако страсти не утихают. Пресловутый антропологический подход набирает обороты, вытесняя из отечественной уголовно-правовой доктрины малейшие этатистские проявления. При этом совершенно игнорируется то обстоятельство, что суть антропологического подхода заключается прежде всего в обеспечении разумного баланса между интересами личности, общества и государства.

Хотелось бы обратить внимание еще на один аспект, связанный с идей приведения национального уголовного законодательства в соответствие с европейскими «стандартами». Здесь уместно будет привести наименования некоторых разделов особенных частей уголовных кодексов европейских государств. Так, например, раздел II Уголовного кодекса Швейцарии предусматривает ответственность за преступные деяния против имуще- 
ства, раздел IX - за преступления против общественного транспорта, раздел XIII - за преступления против обороны страны, а раздел XVIII - за преступные деяния против служебных обязанностей.

Раздел VIII Уголовного кодекса Австрии объявляет наказуемыми преступные деяния против покоя умерших, раздел XII - деяния против достоверности документов, а раздел XVII - деяния против вооруженных сил. Не хочется думать, что Особенная часть УК Украины когда-нибудь будет приведена в соответствии с такими «стандартами».

Поскольку предложенные «революционные» преобразования так и не возымели сколь-нибудь ощутимого эффекта, законодатель к этой идее поостыл. Более того, в 2014 г. в раздел I Особенной части УК Украины вносится ряд изменений и дополнений явно выраженной этатистской направленности. Санкции соответствующих статей значительно усиливаются, расширяется круг деяний, за совершение которых возможно назначение пожизненного лишения свободы, во все статьи этого раздела (кроме ст. 1141) вводится дополнительное наказание в виде конфискации имущества. Причем ради этого законодатель поломал традиционные представления о конфискации имущества как наказании, применяемом исключительно за корыстные посягательства, внеся соответствующие изменения и в ст. 59 УК Украины.

Как уже подчеркивалось, государство традиционно ставило и ставит перед уголовным правом зачастую чисто экономические задачи. Попыткой очередного решения проблемы наполнения доходной части бюджета уголовно-правовыми средствами стало реформирование наказания в виде штрафа. Не преследуя цели всестороннего анализа этих нововведений, хотелось бы обратить внимание на три момента. Первый - это максимальный размер штрафа. На сегодняшний день он составляет 850000 грн, и это в стране с минимальной зарплатой в 1378 грн, причем законодатель оставил за собой право предусмотреть в Особенной части УК Украины и более высокие размеры штрафа. Учитывая, что сегодняшнюю Украину отличает самый высокий за годы независимости уровень безработицы, назначать штрафы в таких размерах просто некому. А если штраф и назначить без учета имущественного состояния виновного, он не будет исполнен. В этом случае, и это второй момент, штраф может быть заменен общественными или исправительными работами, а если он превышает 3 тысячи необлагаемых минимумов, то и лишением свободы вплоть до 12 лет. То есть решение абсолютно простое: если есть деньги, помоги бюджету, нет - сиди. Вопрос о том, а как же в этом случае быть с общими началами и принципами назначения наказания, становится чисто риторическим. И, наконец, третий момент, пожалуй, самый труднообъяснимый. Внеся соответствующие изменения в ст. 12 УК Украины, законодатель ставит в один классификационный ряд штраф как самый мягкий вид основного наказания и лишение свободы на определенный срок или пожизненное лишение свободы (ч. 5 ст. 12). Создалась более чем парадоксальная ситуация, когда, например, занятие игровым бизнесом с санкцией 


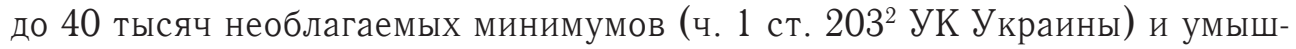
ленное убийство при отягчающих обстоятельствах, предусматривающее возможность пожизненного лишения свободы (ч. 2 ст. 115 УК Украины), стали деяниями одного ряда - особо тяжкими преступлениями. Теперь фактически ничто не мешает законодателю ввести в ту же ч. 2 ст. 115 УК Украины наказание в виде штрафа как однопорядковую с пожизненным лишением свободы форму государственного реагирования на совершенное преступление, доведя до логического завершения исходный тезис «либо плати, либо сиди». Вопрос о восстановлении социальной справедливости по-прежнему остается в разряде риторических.

Впрочем, законодатель предусмотрел и менее «болезненные» способы неуплаты штрафа. Так, согласно ч. 5 ст. 72 УК Украины (норма содержит правила сложения наказаний и зачета срока предварительного заключения) при назначении основного наказания, не указанного в ч. 1 ст. 72 УК Украины, суд обязан полностью освободить осужденного от отбывания такого основного наказания. Штраф в качестве наказания, которое может быть переведено в лишение свободы, в ч. 1 ст. 72 УК Украины не значится. В соответствии с ч. 5 ст. 72 УК Украины в срок предварительного заключения включаются такие сроки: 1) задержание лица без определения следственного судьи, суда; 2) задержание лица на основании определения следственного судьи, суда о разрешении на задержание; 3) содержание лица под стражей; 4) пребывание обвиняемого в соответствующем стационарном медицинском учреждении при проведении судебно-медицинской или судебно-психиатрической экспертизы; 5) пребывание лица, отбывающего наказание, в учреждениях предварительного заключения для проведения следственных действий либо участия в судебном рассмотрении уголовного производства. Таким образом, исполнение штрафа, назначенного в качестве основного наказания, например, за занятие игровым бизнесом (ст. 2032 УК Украины) или незаконную приватизацию государственного, коммунального имущества (ст. 233 УК Украины), становится невозможным, если к обвиняемому применялось предварительное заключение независимо от срока последнего.

Поскольку штраф в указанных статьях предусмотрен в качестве единственного вида основного наказания, и согласно ст. 51 УК Украины он является самым мягким из основных наказаний (это обстоятельство исключает применение ст. 69 УК Украины), занятие игровым бизнесом или незаконная приватизация утрачивают признак наказуемости в случае, если лица, совершившие эти деяния, подвергались предварительному заключению даже на минимальный срок, хотя по своему статусу и ст. $203^{2}$, и ч. 2 ст. 233 УК Украины являются особо тяжкими преступлениями (ч. 5 ст. 12 УК Украины).

Следующее направление в преодолении кризиса - это идея о том, что пунитивная юстиция себя изжила, необходим ее перевод на так называемые рестаративные рельсы, а основным методом разрешения уголовно-правовых конфликтов должен стать диспозитивный метод. Потерпевший при- 
знается полноценным субъектом уголовных правоотношений, наделяется широким объемом прав, его мнение не просто учитывается, а становится определяющим при решении вопроса об освобождении виновного от уголовной ответственности. Эту идею подхватывает также Уголовный процессуальный кодекс Украины 2012 г., где существенно расширен перечень уголовных производств в форме частного обвинения (ст. 477), конституировано соглашение о примирении между потерпевшим и подозреваемым или обвиняемым (ч. 1 ст. 468) и так далее. Не отрицая в принципе возможность использования диспозитивных начал при разрешении уголовно-правовых конфликтов, следует особо подчеркнуть, что уголовное право является публичной отраслью с ярко выраженным императивным характером. Потерпевший по тем или иным мотивам может простить преступнику все. Но насколько благороден этот жест для отдельного человека, настолько он опасен для общества в целом. Безбрежное проникновение диспозитивных начал в уголовно-правовую материю может не только лишить потерпевшего необходимой защиты (достаточно вспомнить расхожую на практике ссылку на наличие гражданско-правовых отношений между виновным и потерпевшим как на основание отказа в возбуждении дела), но и отбросить уголовное право к его истокам - головщине и Русской правде, полностью лишив самостоятельности и собственного предмета правового регулирования.

Впрочем, все эти направления в преодолении кризиса уголовного права меркнут на фоне развернувшейся широкомасштабной борьбы с коррупцией, в которой, по мнению законодателя, пальма первенства, конечно же, должна принадлежать уголовно-правовым предписаниям. Надо сказать, что отечественная уголовно-правовая и криминологическая наука располагала достаточно солидными наработками по этой теме. Однако законодатель предпочел иной путь - путь простого механического заимствования положений международных конвенций, посвященных борьбе с коррупцией, причем по элементарному принципу: чем детальнее заимствование, тем выше ставки на получение очередного кредита от Международного валютного фонда. Отечественного законодателя абсолютно не смущает ни тот факт, что нормы конвенций носят сугубо рекомендательный характер, ни то обстоятельство, что национальное законодательство доброй старой Европы очень консервативно и мало подвержено конъюнктурным колебаниям.

Панацея виделась прежде всего в криминализации коррупции. Коррупция - понятие не уголовно-правовое, оно характеризует определенное явление, которое имеет различные формы проявления, поэтому не может быть криминализировано по определению. Эффект криминализации в данном случае не превышает эффект от криминализации женской преступности или преступности экономической. Однако именно отсутствие в уголовном законе термина «коррупция» многими рассматривалось как основное препятствие по ее искоренению. В итоге законодатель конституирует это понятие через понятие коррупционных преступлений (заметим, 
что европейское законодательство не оперирует этим понятием, и ни одна из конвенций не настаивает на его обязательном закреплении в УК Украины). Понятие последних не дается, а предлагается перечневый подход, при котором коррупция выходит за пределы своей естественной среды обитания (сферы публичного управления) и искусственно помещается в те сферы, где она по определению «не живет». Учитывая, что к числу коррупционных преступлений отнесен также подкуп работника предприятия, учреждения или организации, не являющегося должностным лицом, в число коррупционеров наконец-то попали врачи и учителя.

Позитивный результат от материализации коррупции весьма сомнителен, а вот негативный побочный эффект такого решения, на наш взгляд, уже имеет место. Во-первых, в уголовном законодательстве появляется новый признак преступления - коррупционность, что не только противоречит ч. 1 ст. 11 УК Украины, где содержится определение преступления, и принципам построения Особенной части, которая соответствующий раздел не предусматривает, но и создает определенные условия для искусственного усиления уголовно-правовых мер без необходимого уголовно-правового обоснования. Во-вторых, предложенные ограничения по применению различных видов освобождения от уголовной ответственности, наказания и его отбывания в определенной мере противоречат как Конституции Украины, которая жизнь человека, его права и свободы провозглашает наивысшей социальной ценностью, так и задачам уголовного законодательства, главная из которых - правовое обеспечение охраны прав и свобод человека и гражданина. По логике законодателя «коррупционные преступления» (объектом которых так или иначе является правильное, эффективное функционирование государственного аппарата) являются наиболее опасными, поскольку никаких ограничений по применению ст. ст. 45, 46, 47, 75 и других при совершении преступлений против прав и свобод личности закон не содержит. В-третьих, законодательные представления относительно круга коррупционных преступлений как преступлений, связанных с предоставлением/получением неправомерной выгоды, позволяет включить сюда также соответствующие деяния в частной сфере. Хотя в отечественной науке уголовного права неоднократно подчеркивалось, что коррупционная преступность ограничивается публично-правовой сферой. Европейские конвенции хоть и рекомендуют криминализировать определенные деяния в частном секторе, вовсе не настаивают на их обязательном понимании как коррупционных преступлений. При таком подходе предназначение уголовно-правовых предписаний, направленных на обеспечение нормального функционирования публично-правовой сферы, полностью утрачивается. Борьба с коррупцией превращается в самоцель, своеобразную «охоту на ведьм». Возникает соблазн поступиться и другими принципами уголовного права, например конституционным принципом личной ответственности, и «сконструировать» институт квазиответственности юридических лиц. Можно даже отойти от позиций «уголовного права деяния» и предусмотреть возможность при- 
менения уголовно-правовых мер по иным основаниям, переориентировав отечественное уголовное законодательство на иное генеральное направление в регулировании преступного поведения лица - на «уголовное право деятеля», когда применение уголовно-правовых мер связывается не с деянием, а с моральной «испорченностью» личности. В ряде законопроектов (например, в законопроекте № 4057), направленных на реформирование института специальной конфискации, предлагается положительно решить вопрос о возможности признания лица виновным несудебными органами и фактически абстрагироваться при применении уголовно-правовых мер от положений, касающихся действий уголовного закона во времени. Вот только величие уголовному праву такие решения законодателя вернуть не в состоянии.

Вполне предвидя всевозможные обвинения в ретроградстве, в заключение хотелось бы особо подчеркнуть то обстоятельство, что автор не против устранения старых, отживших форм и вовсе не является противником нововведений, если только они обусловлены реальными потребностями. Мы стремимся показать, что уголовное законодательство - это не «тришкин кафтан», на котором обязательно должен отметиться каждый народный избранник; механическое перенесение чужих положений в отечественную правовую реальность будет иметь нулевой эффект, но, к сожалению, способно разрушить принципы и конструкции, формировавшиеся веками. По нашему мнению, каждое изменение уголовного закона должно быть тщательно спрогнозировано, и здесь свое веское слово еще должна сказать уголовно-правовая футурология; перманентные изменения закона, та легкость, которую при этом демонстрирует законодатель, неизменно порождают в обществе нигилизм к уголовно-правовым нормам, а само уголовное право делают ничтожным. Поэтому как нельзя более актуальными остаются слова А.О. Кистяковского, высказанные более ста лет тому назад: «В процессе развития и видоизменения уголовного права нет ничего произвольного, нет скачков, внезапностей и неожиданностей. Напротив, все в нем подчинено общему, свойственному всей природе закону постепенного развития, по которому одна формация явлений рождается из другой, по которому ближайшее последующее мало чем отличается от последнего предыдущего, но где две крайние формации, не утрачивая их родового сходства, коренным образом между собой различаются» [5, c. 120$]$.

\section{Литература}

1. Дубовик О.Л. Кризис уголовного права и уголовно-правовой теории / О.Л. Дубовик // Право и политика. - 2001. - № 2. - С. 130-134.

2. Жалинский А.Э. Немецкая уголовно-правовая наука на смене тысячелетий / А.Э. Жалинский / / Уголовное право. - 2002. - № 4. - С. 136-139.

3. Туляков В.О. Кримінальне право сучасності: криза доктрини чи криза юрисдикцій / В.О. Туляков / / Право України. - 2010. - № 9. - С. 40-46.

4. Туляков В.А. Виртуальность уголовного права: постановка проблемы / В.А. Туляков / / Генезис публічного права: від становлення до сучасності : зб. наук. праць / за ред. С.В. Ківалова, В.О. Тулякова, О.В. Козаченка. - Миколаїв : Іліон, 2011. - С. 5-6. 
5. Кістяківський О.Ф. Елементарний підручник загального кримінального права. Загальна частина / О.Ф. Кістяковський. - репр. вид. - К. : ПАЛИВОДА А.В., 2009. - 906 с.

6. Баулін Ю.В. Вибрані праці / Ю.В. Баулін. - Х. : Право, 2013. - 928 с.

7. Общетеоретическая юрисдикция: учебный курс : [учебник] / под ред. Ю.Н. Оборотова. О. : Феникс, 2011. - 436 с.

8. Жалинский А.Э. Уголовное право в ожидании перемен: теоретико-инструментальный анализ / А.Э. Жалинский. - М. : Проспект, 2009. - 400 с.

9. Бабаев М.М. Провокативная роль уголовного закона / М.М. Бабаев, Ю.Е. Пудовочкин / / Общественные науки и современность. - 2013. - № 4. - С. 78-90.

10. Владіміров Л.Є. Курс кримінального права. Частина перша: основи сучасного кримінального права / Л.Є. Владіміров. - репр. вид. - К. : ПАЛИВОДА А.В., 2010. - 388 с.

11. Діденко С.В. Довкілля як об'єкт кримінально-правової охорони : [навч. посібник] / С.В. Діденко, С.В. Крючек, Г.С. Полішук, Ю.В. Біла, В.О. Миронова. - Х. : Харків юридичний, 2009. $-184 \mathrm{c}$.

\section{А н но т а ци я}

Чугуников И. И. Кризис уголовного права или уголовное право кризиса? - Статья.

В статье анализируются тенденции и противоречия развития уголовно-правовой отрасли. Делается вывод о том, что искусственная трансформация уголовного права, происходящая без учета социальных запросов, возможностей правоприменительной практики и собственных отраслевых постулатов, ведет к образованию специфического феномена - уголовного права кризиса. Предпринимается попытка доказать наличие генетической связи между данным феноменом, с одной стороны, и широкомасштабной ревизией устоявшихся понятий, зачастую имеющей сугубо идеологическую подоплеку, механическим заимствованием уголовно-правового материала из законодательства других стран, слепой имплементацией положений международных конвенций, перманентными изменениями национального уголовного законодательства, не имеющими серьезного уголовно-правового обоснования, но преследующими узко утилитарные цели, отсутствием стратегии развитии уголовно-правовой отрасли - с другой. Предлагается кардинально изменить подходы к нормотворчеству в уголовно-правовой сфере, положив в их основу не конъюнктурные политико-идеологические (экономические) соображения, а реальные потребности общества.

Ключевые слова: уголовное право, отраслевой кризис, причины, пути преодоления, нормотворчество.

\section{А нот а ці я}

Чугуніков I. I. Криза кримінального права чи кримінальне право кризи? - Стаття.

У статті аналізуються тенденції та протиріччя розвитку кримінально-правової галузі. Робиться висновок про те, що штучна трансформація кримінального права, яка відбувається без урахування соціальних запитів, можливостей правозастосовної практики та власних галузевих постулатів, призводить до створення специфічного феномена - кримінального права кризи. Здійснюється спроба довести наявність генетичного зв'язку між цим феноменом, з одного боку, та широкомасштабною ревізією усталених понять, яка найчастіше має суто ідеологічне підгрунтя, механічним запозиченням кримінально-правового матеріалу із законодавства інших країн, сліпою імплементацією положень міжнародних конвенцій, перманентними змінами національного кримінального законодавства, які не мають серйозного кримінально-правового обгрунтування, а переслідують вузькоутилітарну мету, відсутністю стратегії розвитку кримінально-правової галузі - з іншого. Пропонується кардинально змінити підходи до нормотворчості в кримінально-правовій сфері, поклавши в їх основу не кон'юнктурні політико-ідеологічні (економічні) міркування, а реальні потреби суспільства.

Ключові слова: кримінальне право, галузева криза, причини, шляхи подолання, нормотворчість. 


\section{S u m m a r y}

Chugunikov I. I. Crisis of criminal law or criminal law of crisis? - Article.

The article analyzes the trends and contradictions of the criminal law field development. We have made the conclusion that the artificial transformation of the criminal law, occurring without taking into account the social needs, opportunities of law enforcement practices and own industrial postulates lead to the formation of a specific phenomenon, namely the criminal law of crisis. We have made an attempt to prove the existence of a genetic link between this phenomenon, on the one hand, and a large-scale revision of established concepts, often having a purely ideological background, mechanical borrowing of criminal law material from the legislation of other countries, blind implementation of the provisions of international conventions, permanent changes in national criminal law, not having a serious criminal legal justification, but pursuing a narrowly utilitarian purposes, lack of development strategy of the criminal law sector, on the other hand. We have proposed to radically change approaches to rulemaking in the criminal law field, putting not conjunctural political and ideological (economic) considerations, but the real needs of society in its basis.

Key words: criminal law, industrial crisis, causes, ways of overcoming, rulemaking. 